\title{
SELFIE AS PROMPT FOR NARRATIVE WRITING
}

\author{
Lim Seong Pek ${ }^{1}$, Rita Wong Mee Mee ${ }^{2}$, Khatipah Abdul Ghani \\ ${ }^{1}$ Universiti Selangor, Malaysia \\ ${ }^{2}$ Universiti Selangor, Malaysia \\ ${ }^{3}$ Universiti Selangor, Malaysia \\ ${ }^{1}$ limsp@unisel.edu.my, ${ }^{2}$ ritawong@unisel.edu.my, ${ }^{3}$ khatisj@unisel.edu.my
}

\begin{abstract}
The evolution of pictures has brought changes to communication in the current time. From smoke signal to smartphones as a medium of communication, has enabled people to keep in touch with one another easier. The development of technology produces internet which is essential to every humankind around the world. With the help of internet, people could now upload pictures, especially Selfies, and post them on social media for others to view and respond to them. Through this medium of sharing over the social media, Selfies are used to deliver messages to facilitate communication better by saying their mind out on what they see and think. Hence, this study was carried out to examine the effects of Selfie as prompt to generate ideas for narrative writing among undergraduates in a local higher education in Malaysia. The findings had shown significant improvement in undergraduates' writing in term of ideas coherency and text length. It was observed that undergraduates were able to narrate their experiences and stories related to their own Selfies as compared to non-pictorial writing. As a whole, the use of Selfie as prompt had improved undergraduates' writing ability as well as their level of confidence in language expression.
\end{abstract}

Keywords: Selfie, Writing Prompt, Narrative Writing

\section{INTRODUCTION}

The introductory of mobile phone technology has also come to exemplify technological aggregation. It is not any more a simple phone with a camera but also internet access portal with various functions. Davies (2014) explained that before the era of smartphones surfaced there was no term declared for the technique used when taking a photo of oneself with an extended arm. The growing trend of the 'selfie' has now become a daily routine for millions of teenagers in 2014. Humphrey (2013) stated in her article that selfies hint at a rapidly growing preference for online conversations that prioritize images over words. In the interview conducted by Humphrey for her research, her respondent says that selfies keep the connection visually, which is more impactful than just a simple text. Photos help people feel connected, especially when they are not involved in many real-life conversations and interactions.

In consideration of the paradigm shift from one generation to another has brought different characteristics and traits to the institutions of higher education. Their learning needs reflect a changing world, especially in view of new technology. For institution to have the knowledge and skills of up-to-date education technology, the institutions of higher education need to be proactive in making this happen. As stated by McCrindle (2016), each generation has been associated with various characteristics and traits that loosely define them as a cohesive group. At present, undergraduates of Generation $\mathrm{Z}$ have become an important community of the institutions of higher education. The Generation $Z$ children are also known as "Digital Natives" that born between 1995-2010. Hence, teaching the students of current generation has brought about the application of what are related to them. 
Developing the undergraduates' ability in writing of the current generation in institutions of higher education is one of the major problems faced by educators today. Concerns pertaining graduates level of communicative competence in English language to better prepare them for the job market have rose dramatically (Osman et al, 2010). The undergraduates will only use English language when they are asked to and only when the opportunity arises during classroom lessons. Hence, many find it difficult to generate ideas to begin writing. Muhsin (2016) confirmed that the students learning English often make mistakes and commit errors while learning English. He added that, in order for the students to generate ideas and write well, students are required to master writing skills especially when they are trying to arrange sentences or use tenses for writing. As a result, they write sentences with incorrect grammar that consequently distort the development of the ideas.

In this study, the use of Selfie as prompt for language writing has played a major contribution to the field of education. Selfie is a photographic object that initiates the transmission of human feelings in the form of a relationship between individuals. A selfie is also a practice - a gesture that can send different messages to different individuals, communities, and audiences. This gesture may be dampened, amplified, or modified by social media censorship, social censure, misreading of the sender's original intent, or adding additional gestures to the mix, such as likes, comments, and remixes. In other words, the use of selfie provides a sense of ownership in expressing oneself through visuals.

\section{METHOD}

The research site was chosen based on the availability of the samples and with the convenience of gathering data. According to Groves et al (2009), convenience sampling allows a researcher to gather primary data from members of population who are already available. The sampling method was chosen due to the fact that the course offered for that particular semester was fixed and it was not possible in choosing participants at random. Moreover, this research site was chosen with an intention to examine the effectiveness of selfie in generating ideas for writing activities among undergraduates studying in the institution.

\section{Experimental Study}

The experimental research design was used to determine if a specific treatment, Selfie in this study, influences the outcome (Cresswell, 2014). A writing task was assigned to all 64 undergraduates as a pre-test in order to measure their overall writing performance related to development of ideas and language proficiency. The essays were rated by two independent raters, via a 6-band scale. After marking, two experimental groups were formed with 33 undergraduates while the other with 31 undergraduates was recognised as control groups for the study.

At post-test, respondents' final writing scripts from both groups were collected as a source to provide valuable information in helping the researchers to determine the effectiveness of selfie in helping these undergraduates in mastering writing skills. Samples were collected and rated by raters to identify the differences in undergraduates' writing. All the essays from respondents were scored independently by the raters to show the effects of selfie as treatment towards the undergraduates' writing.

The papers were rated on a holistic 6-band ( 1 to 6 scales) in which Band 6 is the higher scores. A total of 20 marks were allocated for content as another 10 marks were allocated for language. 
In this section, the data was analysed based on both content and language scores. The research procedure are shown in the figure below:

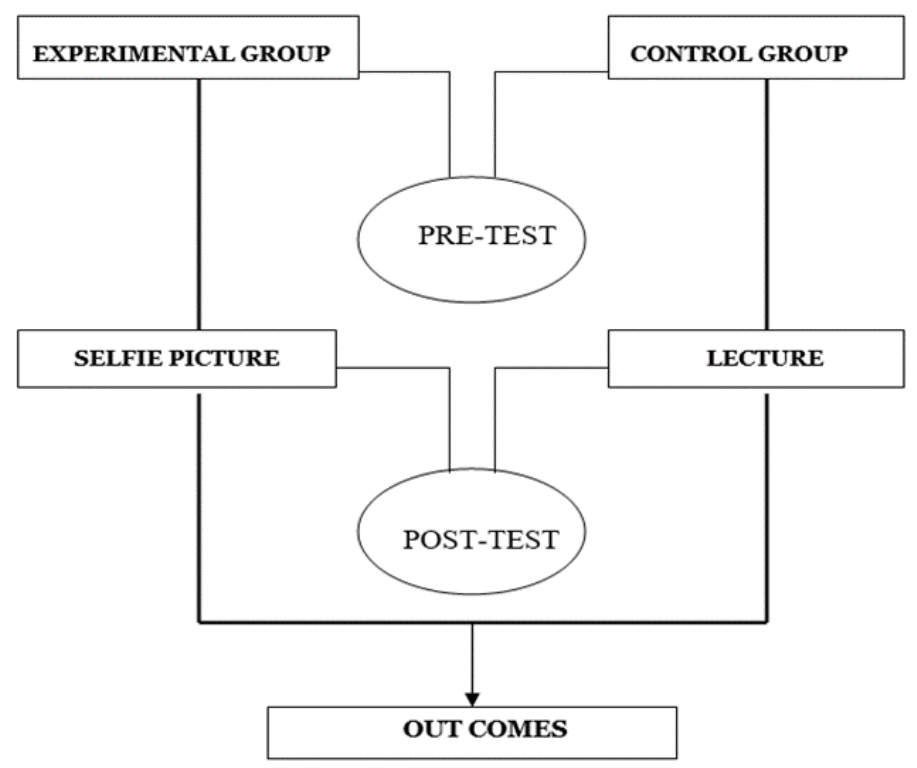

Figure 1. Experimental Research Procedure

\section{RESULTS AND DISCUSSION}

\section{Results}

\section{Analysis on Content Score}

\section{Control Group (CG)}

Analysis of t-test on content score for CG was pre-tested and post-tested. The scores are as shown in table as follows.

Table 1. Paired Samples Statistics on Content for CG

\begin{tabular}{lcccc}
\hline & Mean & $\mathrm{N}$ & $\begin{array}{c}\text { Std. } \\
\text { Deviation }\end{array}$ & $\begin{array}{c}\text { Std. Error } \\
\text { Mean }\end{array}$ \\
\hline PRCONT & 7.74 & 31 & .773 & .139 \\
\hline PSCONT & 7.90 & 31 & .473 & .085 \\
\hline
\end{tabular}

The paired samples statistics in Table 1 indicates that there was a significant difference in mean scores in which the post-test score (7.90) which was higher than that of the pre-test score (7.74). The mean scores had shown a significant different where the undergraduates' content development in an overall had a slight increase with the use of conventional writing class treatment.

\section{Experimental Group (EG)}

The analysis of t-test below shows the content score for EG. EG was pre-tested and post-tested and the scores for content are as shown in Table 2. 
Table 2. Paired Samples Statistics on Content for EG

\begin{tabular}{ccccc}
\hline & Mean & $\mathrm{N}$ & $\begin{array}{c}\text { Std. } \\
\text { Deviation }\end{array}$ & $\begin{array}{c}\text { Std. Error } \\
\text { Mean }\end{array}$ \\
\hline PRCONT & 7.06 & 33 & .864 & .150 \\
\hline PSCONT & 7.70 & 33 & .467 & .081 \\
\hline
\end{tabular}

The paired samples statistics in Table 2 indicates that there was a significant difference in mean scores in which the post-test score (7.70) which was higher than that of the pre-test score (7.06). The mean scores had shown a significant different where the undergraduates' content development in EG had an overall increase after the introduction of Selfie as treatment for writing activities.

\section{Analysis on Language Score}

Control Group (CG)

The analysis of t-test below shows the language score for CG. The language score for CG was pre-tested and post-tested and the scores are as shown in Table 3.

Table 3. Paired Samples Statistics on Language for CG

\begin{tabular}{ccccc}
\hline & Mean & $\mathrm{N}$ & $\begin{array}{c}\text { Std. } \\
\text { Deviation }\end{array}$ & $\begin{array}{c}\text { Std. Error } \\
\text { Mean }\end{array}$ \\
\hline PRLANG & 6.29 & 31 & .864 & .155 \\
\hline PSLANG & 7.13 & 31 & .499 & .090 \\
\hline
\end{tabular}

The paired samples statistics in Table 3 indicates that there was a significant difference in mean scores in which the post-test score (7.13) which was higher than that of the pre-test score (6.29). The mean scores had shown a significant different where the undergraduates' language performance in CG had an overall increase with the implementation of conventional writing lessons.

\section{Experimental Group}

The analysis of t-test below shows the language score for EG. EG was pre-tested and posttested and the scores are as shown in table as follows.

Table 4. Paired Samples Statistics on Language for EG

\begin{tabular}{ccccc}
\hline & Mean & $\mathrm{N}$ & $\begin{array}{c}\text { Std. } \\
\text { Deviation }\end{array}$ & $\begin{array}{c}\text { Std. Error } \\
\text { Mean }\end{array}$ \\
\hline PRLANG & 6.30 & 33 & .984 & .171 \\
\hline PSLANG & 7.21 & 33 & .415 & .072 \\
\hline
\end{tabular}

The paired samples statistics in Table 4 indicates that there was a significant difference in mean scores in which the post-test score (7.21) which was higher than that of the pre-test score (6.30). The mean scores had shown a significant different where the undergraduates' language performance in this group had increased with the integration of Selfie into writing lessons. 


\section{Discussion}

Based on the data tabulated above, it was found that there was a significant difference between the treatment and respondents' writing performance. The used of selfie as prompt for writing activity has proven to be an effective strategy in helping undergraduates to generate ideas for writing in English language classroom. In response to Gashout (2014), in writing, student writers must get used to drafting, revising, and redrafting for several time before producing a final piece. Hence, with this study, educators lecturing English language proficiency courses in institutions of higher education could incorporate selfie as an instructional material to help undergraduates to expand their writing tasks.

In general, narrative writing is one of the many writing styles being put into practice in the current curriculum both in schools and during English language proficiency courses. Incorporating selfie as an activity for writing allow undergraduates to work at their own pace. This will indirectly trigger learning how to learn skills. With the time and contact hours a student might have at the institution of higher education, English should be practised on their own rather than relying too much on their lecturers (Pek \& Mee, 2015). Notwithstanding, there is a need for English language educators to look for new strategies and teaching techniques in making the classroom fun. It is, therefore, Selfie has the ability to trigger undergraduate's motivation in communication and somehow generate opportunities interaction. Through this, language educators may be able to produce desired learning outcomes while lecturing.

\section{CONCLUSION}

Hence, in this study, the integration of Selfie as a tool to improve undergraduates' writing ability may prove to be ideal. Pictures may not only prevalent to learning to write, it also helps to motivate in communication competence. Similarly, Selfie works like other suggested pictures where many have used it to generate interaction with others through social media. So, it is suggested that, teachers and educators should integrate selfie during language education in classroom. The usage of selfie in language classroom should be increased as it can be very essential in promoting learner autonomy, especially undergraduates in institutions of higher education, where they could easily relate their past experience into their writing task.

\section{ACKNOWLEDGMENTS}

We would like to thank all the respondents for making this study a success. Not to forget the raters and all our beloved friends and family who are always there support and motivate us during conducting this study. We hope this study would be useful to future researchers who need references.

\section{REFERENCES}

Creswell, J. W. (2014). Research Design: Qualitative, Quantitative and Mixed Methods Approaches (4th ed.). Thousand Oaks, CA: Sage.

Davies, M. (2014). The "Selfie" Trend. Retrieved from http://www.huffingtonpost.co.uk/matthew-davies/the-selfie-trend_b_6084704.html

Gashout, M. (2014). Incorporating the facilitative feedback strategies together with the process approach to improve students' writing. International Journal of Education and Research, 2(10), 637-646. 
Groves, R. M., Fowler, F. J., Couper, M. P., Lepkowski, J. M., Singer, E., \& Tourangeau, R. (2004). Methods of data collection. Survey methodology, 162-164.

Humphrey, K. (2013). As Popular As Ever, Selfies Are Changing The Way We Communicate. Retrieved from http://www.startribune.com/as-popular-as-ever-selfies-are-changing-theway-we-communicate/219856941/

McCrindle, M. (2016). Generation Z characteristics. Info@ mccrindle.com.au. Retrieved from http://generationz.com.au/characteristics/

Muhsin, M. A. (2016). Analysing the students errors in using simple present (A case study at Junior High School in Makassar). Pacific Science Review B: Humanities and Social Sciences, 2(3), 81-87.

Osman, Pandian, Daud, Don Salleh, Harun, Yusof, S Rethinasamy, and Ma'alip (2010). Future Direction of Language Education in Malaysia. Ministry of Higher Education. Bangi: UKM Press.

Pek, L. S., \& Mee, R. W. M. (2015). Selfie: Engaging Life Experiences into Writing. Malaysian Journal of Distance Education, 17(2). 